\title{
REPENSANDO A INTERDISCIPLINARIDADE: CONTRIBUTOS À ATUAÇÃO DO ASSISTENTE SOCIAL NA ÁREA DA SAÚDE
}

\author{
THE RETHINKING INTERDISCIPLINARITY: CONTRIBUTIONS TO THE \\ PRACTICE OF THE SOCIAL WORKER IN HEALTH
}

\author{
Nilsen Aparecida Vieira Marcondes ${ }^{1}$ \\ Elisa Maria Andrade Brisola ${ }^{2}$ \\ Sandra Regina dos Santos ${ }^{3}$ \\ Edna Maria Querido de Oliveira Chamon ${ }^{4}$
}

\section{RESUMO}

A trajetória reflexiva que segue está apoiada numa revisão de literatura. O foco da análise voltase para o tripé Interdisciplinaridade, Formação Continuada e Serviço Social considerando que isso traz subsídios para o profissional envolvido com ações no âmbito da saúde. Entretanto, considera-se também bastante pertinente, enquanto elementos complementares à análise, a exposição de algumas ideias referentes à conceituação da palavra, resgate histórico, motivações para se refletir e agir interdisciplinarmente, reflexos destas atitudes dentro dos ambientes acadêmicos, societário, e por fim sobre os desafios que se colocam aos que desejam trilhar por este caminho.

PALAVRAS-CHAVE: Revisão de Literatura. Interdisciplinaridade. Formação Continuada. Serviço Social.

\section{ABSTRACT}

The reflexive journey that follows is supported by a literature review. The focus turns to the tripod Interdisciplinarity, and Social Work Continuing Education considering that it brings benefits to the professional working in health actions. However, it is also quite appropriate as complementary elements to the analysis, presenting some ideas concerning the concept of the word, redemption history, motivation to reflect and act in an interdisciplinary, reflected these attitudes within academia, corporate, and finally about the challenges facing those who wish to tread this path.

KEYWORDS: Literature Review. Interdisciplinarity. Continued background. Social Work.

\footnotetext{
${ }^{1}$ Assistente Social, Mestre em Desenvolvimento Humano. Formação, Políticas e Práticas Sociais (UNITAU). Telefone 123912 3352, e-mail: nilsenmarcondes@gmail.com.

${ }^{2}$ Assistente Social, Doutora em Serviço Social (PUC São Paulo) é Docente no Curso de Pós-Graduação Stricto Sensu da UNITAU: Mestrado em Desenvolvimento Humano. Formação, Políticas e Práticas Sociais. E-mail: elisabrisola@uol.com.br.

${ }^{3}$ Assistente Social, Mestranda do Curso de Pós-Graduação Stricto Sensu da UNITAU: Mestrado em Desenvolvimento Humano. Formação, Políticas e Práticas Sociais. E-mail: sandrasocial30@yahoo.com.br.

${ }^{4}$ Coordenadora do Programa de Pós-Graduação Stricto Sensu em Educação e Desenvolvimento Humano da Universidade de Taubaté. E-mail: edna.chamon@gmail.com. Serv. Soc. \& Saúde, Campinas, SP v. 11, n. 1 (13), p. 67-98 jan./ jun. 2012 ISSN 1676-6806
} 


\section{INTRODUÇÃO}

A interdisciplinaridade tem se apresentado como perspectiva e desafio para os assistentes sociais que buscam a formação continuada e, consequentemente, o enfrentamento da questão social. Ademais, a interdisciplinaridade se faz presente não apenas como estratégia de ação, mas também de reflexão, sendo considerada como condição essencial para formação e atuação de maior qualidade, dada sua relevância na totalidade da vida humana em todos os aspectos.

Intenciona-se que a ênfase dada à interdisciplinaridade dentro do contexto da formação continuada, possa contribuir com indicativos que despertem desejos de aprofundamento sobre a questão no campo do ensino, da pesquisa e atuação prática. Este desejo obviamente se encontra vinculado à certeza de que na direção da interdisciplinaridade há muito o que se fazer porque se trata de tarefa inacabada a ser construída permanentemente, dada à profundidade de seu significado e ao momento histórico favorável que se apresenta na cotidianidade.

\section{CONCEITUANDO O TERMO}

Interdisciplinaridade palavra de pronuncia difícil, mas portadora de significado e consequências surpreendentes. O debate sobre a importância do agir e pensar de forma interdisciplinar é corrente e vem ganhando espaço dentro dos ambientes acadêmicos (graduação, pós-graduação, na pesquisa e na extensão) e societários. Isso se justifica mediante comprovado alcance positivo de seus resultados teórico-práticos. "O diagnóstico destas novas áreas do conhecimento leva a reconhecer-se seu grande potencial científico, a julgar por seu forte crescimento no último decênio e pela existência de experiências ricas e inovadoras” (BRASIL, 2010, p. 137).

Os órgãos de governo que financiam a Pós-Graduação brasileira e a agência responsável pela avaliação do sistema - a CAPES - estarão às voltas, na nova década, com a Grande Área Multidisciplinar, uma área da pesquisa caracterizada pela expansão acelerada, vista por muitos como algo crítico e preocupante; mas que, reconhecidamente, abarca, naquelas experiências bem sucedidas, problemas estimulantes, de ponta do conhecimento, propiciando novos e instigantes desafios intelectuais (BRASIL, 2010, p. 133).

O segmento [interdisciplinar] teve um crescimento vertiginoso na última década, evidenciado pelas estatísticas que mostram que [esta] Grande Área teve, de longe, a maior taxa de crescimento do sistema da CAPES (59,8\%) [...] colocando a Grande Área Multidisciplinar em 
pé de igualdade com áreas tradicionais como Engenharias $(11,2 \%)$ e Ciências Agrárias (11\%) e mesmo em posição superior às Ciências Biológicas (8,1\%) e Linguística, Letras e Artes (5,6\%). [...] Quanto ao mais, pode-se dizer que esta Grande Área continuará a crescer na próxima década [...]. (BRASIL, 2010, p. 134).

A apreensão do contexto contraditório das diversas realidades que se apresentam, tão necessária para uma reflexão e intervenção, advém justamente desta proposta interdisciplinar. Tal assertiva remete a compreensão de que, caso contrário se incorreria ao fracionamento do conhecimento o que levaria a uma "aproximação estruturalista da realidade e a uma análise unilateral” (SÁ, 2010, p. 8), sem levar em conta a totalidade do real.

Numa primeira instância, faz-se necessário compreender no vernáculo pátrio o sentido da palavra quando comparada com suas similares. Para isso, parte-se de algumas definições que englobam os prefixos multi, inter, pluri e trans. Entretanto, é importante considerar que não obstante as diferenças, todas possuem, na sua essência, uma similaridade, ou seja, todas focam a reflexão ou ação conjunta na busca de melhores resultados.

A partir da busca no dicionário, encontrou-se as seguintes definições: Multidisciplinaridade “1. é o conjunto de múltiplas disciplinas, 2. Estudo pela adição de disciplinas ou campos disciplinares independentes para aprofundar um conhecimento, um saber” (BUARQUE DE HOLANDA, 2010, p. 520). Interdisciplinaridade “aquilo que é comum a dois ou mais campos disciplinares inter-relacionados” (ibid., p. 433). Pluridisciplinaridade "relativo a diversas disciplinas de um mesmo campo disciplinar, ou a vários campos disciplinares interligados ou inter-relacionados” (ibid., p. 593). Transdisciplinar “o que integra ou visa a integrar várias disciplinas” (ibid., p. 750).

De acordo com a definição de Buarque de Holanda (2010), chega-se ao entendimento de que a multidisciplinaridade significa o primeiro passo para se chegar à interdisciplinaridade porque o prefixo “multi” diz respeito à “adição”, “soma” no sentido matemático. Para a autora Ely (2003, p. 114), a multidisciplinaridade é representada por um "trabalho que acontece de forma isolada, geralmente com troca e cooperação mínima entre as disciplinas”. Diante do exposto, compreende-se que a multidisciplinaridade, considerada como possibilidade de troca e cooperação entre áreas de conhecimento e intervenção, pode tornar-se um potencial caminho intermediário em direção à interdisciplinaridade. 
Quanto à pluridisciplinaridade partindo da definição da palavra como relativa a diversas disciplinas de um mesmo campo disciplinar, ou a vários campos disciplinares interligados ou inter-relacionados, significa que ela, de certa forma, contém o que é multidisciplinar, mas também o que é interdisciplinar. Entender isso significa, portanto, conceber a pluridisciplinaridade como aproximação, unidade entre os diferentes, mas também não aproximação, não unidade naquilo que é comum entre os diferentes, ou seja, simplesmente envolver disciplinas ou ações sem relação aparente entre elas. $\mathrm{Na}$ pluridisciplinaridade "as disciplinas se agrupam de forma justaposta, com cooperação, porém cada profissão decide isoladamente” (ELY, 2003, p. 114).

Sampaio et al. (2010, p. 83) coloca que:

Por multi e pluridisciplinaridade entende-se uma atitude de justaposição de conteúdos de disciplinas heterogêneas ou a integração de conteúdos numa disciplina, alcançando a integração de métodos, teorias ou conhecimentos [... ambas] constituem etapas para a interação e para a interdisciplinaridade [...]. A transdisciplinaridade seria o nível mais alto das relações iniciadas nos níveis de multi, pluri e interdisciplinaridade.

Segundo Ely (2003, p. 114) o conceito de transdisciplinaridade, definida como “aquilo ou aquele que integra ou visa a integrar várias disciplinas”, leva a pensar em movimento, em interação, em algo não estático, seja no campo da reflexão ou da ação. A transdisciplinaridade se coloca dentro de um contexto no qual é possível refletir sobre como unir e como articular os diferentes, respeitando, evidentemente, a diversidade de cada um. Na transdisciplinaridade “a coordenação é realizada por todas as disciplinas e interdisciplinas, propondo a criação de um campo com autonomia teórica, disciplinar e operativa” (ibid., p. 114).

Já a interdisciplinaridade agregada ao prefixo "inter” traz em seu conceito algo mais profundo quando: "aquilo que é comum a dois ou mais”, não significa simplesmente "soma”, vai além, “funde-se” em aspectos que são comuns, quer dizer “é um, mas composto por vários" de forma que os "vários" não se perdem em suas especificidades, mas profundamente ligados, por aquilo que lhes é comum. É interessante é importante compreender isso. É desta compreensão que se parte para a reflexão e posteriormente à ação. Na interdisciplinaridade “as relações profissionais e de poder tendem à horizontalidade, as estratégias de ação tendem a ser comuns e estabelece-se uma troca recíproca de conhecimento entre as diferentes disciplinas” (Ibid., p. 114). Segundo a mesma autora: 
A interdisciplinaridade situa-se, portanto, em um nível avançado de cooperação e coordenação, de forma que todo conhecimento seja valorizado, com relações de intersubjetividade e de copropriedade baseadas em uma atitude de diálogo. Nesta interação e articulação entre as diversas áreas do saber envolvidas, é preciso haver respeito à autonomia e à criatividade inerente a cada uma destas áreas, para que não sejam influenciadas ou excluídas deste processo (ELY, 2003, p. 114).

Ainda em termos de conceituação, o V Plano Nacional de Pós-Graduação

(PNPG 2011-2020) apresenta as seguintes elucidações:

Entende-se por Multidisciplinar o estudo que agrega áreas do conhecimento em torno de um ou mais temas, no qual cada área ainda preserva sua metodologia e independência [... e] por Interdisciplinaridade a convergência de duas ou mais áreas do conhecimento, não pertencentes à mesma classe, que contribua para o avanço das fronteiras da ciência e da tecnologia, transfira métodos de uma área para outra, gerando novos conhecimentos ou disciplinas e faça surgir um novo profissional com um perfil distinto dos existentes, com formação básica sólida e integradora. [...] Assim, a diferença parece clara e depende do campo semântico dos verbos agregar e convergir, levando a Inter a algo mais exigente, como a fusão de campos, transferência de métodos, conhecimento novo e formação de profissional diferente. Todavia, é indiscutível que também as áreas multidisciplinares visam ao conhecimento novo e à geração de novos produtos, criando uma nova cultura e moldando um novo profissional, adequado às exigências do conhecimento e da pesquisa, como mostram as pesquisas em biotecnologias e em materiais (BRASIL, 2010, p. 135-136, grifos do original).

O navegar no barco da interdisciplinaridade permite compreender que é possível criar e reconhecer os saberes consequentes da integração entre as diversas disciplinas. A interdisciplinaridade, além de representar lócus privilegiado de aprendizagem para aqueles que a praticam, se configura também como espaço de construção de alternativas inovadoras, por parte de cada área de saber específica, no que tange ao aprimoramento das respostas que devem oferecer as demandas de trabalho que se apresentam. Dentro desta perspectiva, verifica-se, portanto que a interdisciplinaridade não expressa pura e simplesmente reunião ou somatória de diversas intervenções. Ela envolve uma realidade bem mais significativa na medida em que se pauta no estabelecimento de um objetivo comum, partindo de um espaço sócio ocupacional de intervenção também comum e tendo claramente definidas quais formas de intervenção se deve realizar. É importante compreender isso porque o simples fato de vários profissionais de diferentes disciplinas efetuarem suas ações num mesmo espaço físico não significa que estejam agindo movidos pela interdisciplinaridade. "A interdisciplinaridade é uma relação de Serv. Soc. \& Saúde, Campinas, SP v. 11, n. 1 (13), p. 67-98 jan./ jun. 2012 ISSN 1676-6806 
reciprocidade, de mutualidade, que pressupõe uma atitude diferente a ser assumida frente ao problema do conhecimento, isto é, substituir a concepção fragmentária pela unitária do ser humano” (SAMPAIO et al., 2010, p. 82).

O homem é uma unidade que só pode ser apreendida numa abordagem sintetizadora e nunca mediante uma acumulação de visões parciais. De nada adianta proceder por decomposição, análise e recomposição de aspectos [... porque] esta soma não dará a totalidade humana. É preciso, pois, no âmbito dos esforços com vistas ao conhecimento da realidade humana, praticar intencional e sistematicamente, uma dialética entre as partes e o todo, o conhecimento das partes fornecendo elementos para a construção de um sentido total, enquanto o conhecimento da totalidade elucidará o próprio sentido que as partes, autonomamente, poderiam ter (SEVERINO, 2010, p. 17).

É relevante considerar que o buscar a interdisciplinaridade "não significa a defesa de um saber genérico, enciclopédico, eclético ou sincrético. Não se trata de substituir as especialidades por generalidades” (SEVERINO, 2010, p. 15). E ainda de acordo com Severino (2010), na interdisciplinaridade, aquele conhecimento específico que cada profissional possui e que foi fundamentado e consolidado conforme sua área de saber não será generalizado, pelo contrário, as especificidades e delimitações devem permanecer tanto no campo da intervenção social, como na ação pedagógica, quanto na prática de pesquisa. Refrações desta proposição afirmativa se fazem presentes também na fala da autora Chamon (2007) ao afirmar que a interdisciplinaridade aporta a necessidade da presença das especialidades.

[...] a interdisciplinaridade não prescinde do especialista. [...] ela surge da frequentação mútua das várias disciplinas acadêmicas já existentes e estabelecidas, caso contrário corre o risco de cair na generalização fácil e superficial, em um "holismo difuso". Ou seja, a interdisciplinaridade nasce do trabalho do especialista a partir de seu esforço para ver o "mundo de fora de seu mundo" (ibid., p. VIII, grifos da autora).

\section{BREVE RESGATE HISTÓRICO DA FRAGMENTAÇÃO DO SABER}

$\mathrm{Na}$ atualidade, a interdisciplinaridade emerge "como crítica a uma educação fragmentada permitindo uma reflexão aprofundada sobre o ensino, apoiando os movimentos da Ciência e da Pesquisa” (SAMPAIO et al., 2010, p. 84). Esta realidade é enfatizada também por Severino (2010, p. 11) ao afirmar que a interdisciplinaridade, enquanto

[...] prática concreta é ainda processo tateante na elaboração do saber, na atividade de ensino e de pesquisa e na ação social [...]. Por isso, todo investimento que pensadores, pesquisadores, educadores, 
profissionais e especialistas de todos os campos de pensamento e ação, fazem, no sentido de uma prática concreta da interdisciplinaridade, representa um esforço significativo rumo à constituição do interdisciplinar.

“A fragmentação do saber originou profissionais cada vez mais especializados, cujas competências isoladas não conseguem atender às exigências e complexidades dos problemas atuais” (ELY, 2003, p. 114). E nesta direção, Lara (2007, p. 74) reforça afirmando que não se pode negar que um "conhecimento fragmentado e acentuado pela falta de diálogo entre as áreas consequentemente colabora para a compreensão do homem e da sociedade como partes isoladas da dinâmica social e da tecedura histórica”. Neste contexto, a interdisciplinaridade é considerada pela autora Chamon (2007) como:

[...] palavra da moda. Muito discutida e valorizada em todas as áreas do conhecimento, sua prática, entretanto, é pouco concretizada, o que pode ser explicado, em parte, pela longa tradição das especialidades, ainda muito em voga, a qual constitui uma das marcas da modernidade (ibid., p. VII).

Por outro lado, a tentativa de se buscar a unidade no campo do conhecimento, que consequentemente traz repercussões para a área de ensino, pesquisa e intervenção social, tem sido preocupação permanente de alguns profissionais que ao se esforçarem para atuar na contramão desta fragmentação do saber, oportunizam a criação de espaços, onde "o homem da especialidade possa vir a ser ao mesmo tempo um homem da globalidade, desencadeando assim uma ação interdisciplinar” (SAMPAIO et al., 2010, p. 82).

Ao se envidar esforços na construção de uma trajetória interdisciplinar é preciso considerar ainda, a existência de uma profunda conexão entre toda ação da consciência com a necessidade da atuação prática. Contudo, no desenvolvimento da história da humanidade e conforme as relações entre os homens foram se tornando complexas do ponto de vista social e psíquico, esta experiência íntima da consciência com o agir interventivo, foi gradativamente perdendo sua nitidez e se fragmentando enquanto unidade indivisível. E nestes espaços vazios decorrentes da fragmentação, foram se alojando novas formas de se pensar, de se analisar, de se compreender o mundo real e de agir nele. Nascia então, uma pluralidade de alternativas de pensamento e de ação que pouco a pouco se consolidava. E com isso, gradativamente "o universo se transforma num pluriverso" (SEVERINO, 2010, p. 13).

A exigência da unidade se impõe como força originária. Ainda quando negada pela consciência explícita, ela se insinua sub-repticiamente e se faz também presente e atuante de forma implícita. É o que nos 
revelam os diversos momentos significativos desta longa e épica história da consciência no tecido da história da vida social e cultural da Humanidade (SEVERINO, 2010, p. 13).

É interessante observar este resgate, esta ressignificação da importância da interdisciplinaridade nos dias atuais. E isso ocorre, mesmo que ainda se esteja sob a influência de uma Filosofia que se propôs a justificar a fragmentação da unidade consciência-ação, como é o caso da Filosofia Positivista de Augusto Comte, considerada como o “maior obstáculo à interdisciplinaridade” (SÁ, 2010, p. 9). A justificativa para este posicionamento por parte de alguns autores como Cunha (2008), Sá (2010) e Severino (2010) decorre do fato de tal teoria do conhecimento afirmar que somente a filosofia seria o "denominador comum de todo tipo de conhecimento, teórico ou prático capaz de apreender e desvendar a ordem natural dos acontecimentos históricos” (CUNHA, 2008, p. 48).

Considera-se que “a imposição e a predominância hegemônica de uma metodologia positivista levaram os cientistas a uma fragmentação do saber e ao sacrifício da unidade do real onde a afirmação das especialidades prevalece sobre a busca do sistema do universo” (SEVERINO, 2010, p. 15). Assim, para se retomar a questão da interdisciplinaridade, é necessário reavaliar as heranças deixadas por este Referencial Teórico, não obstante os aspectos positivos que trouxe como a "valiosa contribuição ao denunciar e superar a generalidade da construção do saber metafísico, livrando-nos assim do medo do mundo da naturalidade” (SEVERINO, 2010, p. 16).

O positivismo se autodenomina como filosofia das filosofias, na medida em que acredita "fornecer a regra geral de entendimento e interpretação de todos os acontecimentos históricos, ao mesmo tempo em que delimitava os campos de intervenção da ação humana, fornecendo regras de como fazê-la” (CUNHA, 2008, p. 49). Mediante esta postura compreende-se porque o

[...] positivismo torna-se no limiar da contemporaneidade, o maior responsável pela fragmentação do saber e o maior obstáculo à própria interdisciplinaridade [... e] tematizando de modo específico a questão da natureza [...] consagra a proposta das especializações, que se não chegaram a comprometer o esforço de unificação no âmbito das Ciências Naturais, comprometeu de forma inevitável o âmbito das Ciências Humanas (SEVERINO, 2010, p. 15).

Reconhecido como Doutrina porque se trata de "um conhecimento organizado a partir de um corpo teórico próprio e definido” (CUNHA, 2008, p. 49) o Positivismo, por meio de suas regras metodológicas direcionadas à Ciência, define entre outras 
realidades que "a busca do conhecimento implica a delimitação de um objeto específico de conhecimento" (ibid., p. 50) definindo também que "se tudo estiver em ordem, haverá o progresso reforçando a crença de que o progresso decorre da ordem” (ibid., p. 51). Por conta disso, é debitado ao Positivismo “o ônus da fragmentação do saber, o que exige a prática de uma denúncia e o esforço de superação desta etapa da evolução do saber” (SEVERINO, 2010, p. 16).

Apesar, desta herança positivista a interdisciplinaridade vem sendo recuperada enquanto "momento histórico do discurso humano se expressando nas diferentes camadas sociais e condenando a fragmentação dos especialismos” (MARQUES; RAMALHO, 2010, p. 67). E essa recuperação é muito significativa e oportuna porque:

A retomada da totalidade do conhecimento através da prática interdisciplinar não é uma tarefa fácil, pois tradicionalmente, a sua fragmentação desenvolveu uma cultura de trabalho calcada em profissões essencialmente disciplinares, cuja tomada de decisão se processa de forma isolada, observando apenas as limitações de cada especialização. Como a interação interdisciplinar prevê uma troca recíproca de conhecimento entre as áreas do saber, com o compartilhamento de objetivos comuns para a ação, é compreensível o estabelecimento de relações conflituosas, oriundas de atitudes dominadoras - assumidas por determinados profissionais - que comprometem a interação, inibindo contribuições das demais áreas. (ELY, 2003, p. 115).

É evidente que dada à dimensão universal da interdisciplinaridade, seus efeitos não se limitam a atingir somente uma nação em especial, mas se repercutem pelas terras mais distantes, contribuindo enquanto resposta às demandas de outras nações, na medida em que "a palavra interdisciplinaridade atravessa fronteiras e, atualmente dá a volta ao planeta. Da Nova Zelândia ao Japão, de Portugal à Noruega, do Chile ao Canadá, o termo tem uma utilização corrente” (LENOIR, 2006, p. 2).

No contexto histórico mundial, retomando a questão do resgate da noção de interdisciplinaridade, percebe-se que o uso do termo, da palavra enquanto conceito “é recente, pois foi forjada há menos de cem anos e sua extensão ao domínio da educação é ainda mais recente porque ela data do pós-guerra mundial” (ibid., p. 4). Dentro do contexto europeu a abordagem da interdisciplinaridade é focada mais no nível acadêmico, já na abordagem americana a interdisciplinaridade situa-se no interior da vertente funcionalista.

Em solo brasileiro não se pode falar em interdisciplinaridade como síntese da abordagem europeia e americana, pois nesta nação a cultura local lhe atribuiu nova 
roupagem aproximando-a da abordagem fenomenológica. E a fenomenologia, segundo King (2001 apud ROEHE, 2006, p.153) é “o estudo das formas como algo aparece ou se manifesta, em contraste com estudos que procuram explicar as coisas a partir de relações causais ou processos evolutivos”.

A abordagem fenomenológica considera como fenômeno toda forma com que determinada realidade ou algo se apresenta e enfatiza que qualquer atividade científica está relacionada ao modo de ser do homem, devendo sempre tê-lo como ponto de partida para construção de conhecimentos ou para realização da intervenção prática. A fenomenologia não considera o homem como coisa, pelo contrário o considera como aquele que ilumina, ou seja, aquele que mostra o mundo. Portanto, para Roehe (2006, p. 157-158) “qualquer procedimento científico que exclua a presença humana apaga a luz e consequentemente nada poderia ser visto, porque é a partir do modo humano de ser que qualquer questão epistêmica adquire seu sentido original”.

Existe uma informação histórica relevante no que se refere à preocupação com a questão da interdisciplinaridade, começando pela sua fase intermediária, ou seja, pelo aspecto multidisciplinar. A informação remonta desde os anos de 1990, quando após realização do V Encontro Nacional de Pró-Reitores de Pesquisa e Pós-Graduação foi elaborado o IV Plano Nacional de Pós-Graduação. Estes pró-reitores organizados em grupos de trabalho indicaram quais eixos básicos o IV Plano Nacional deveria enfatizar, e num desses eixos falava-se justamente da "preocupação com a perspectiva multidisciplinar” (BAPTISTA; RODRIGUES, 1992, p. 112).

Desconsiderar a relevância da interdisciplinaridade pode limitar a ação profissional, tanto no plano teórico quanto prático, uma vez que a mesma se configura como necessária, ao mesmo tempo em que é requisitada, pela intricada realidade dos problemas que emergem do contexto societário na atualidade.

\section{ATITUDE INTERDISCIPLINAR E AMADURECIMENTO PROFISSIONAL}

Anterior à reflexão e a ação interventiva é necessário que o profissional primeiramente seja ou queira ser interdisciplinar para posteriormente partir para a reflexão ou ação. Logo, o primeiro passo para exercitar a interdisciplinaridade começa pela atitude. Atitude a ser construída momento por momento, sempre que as ocasiões assim a permitirem ou solicitarem, estando a pessoa inserida nos diversos espaços sócio ocupacionais ou não. Ressalta-se a presença em espaços sócio ocupacionais ou não 
porque a atitude se faz presente em qualquer ambiente onde a pessoa possa estar. Fazenda (2003 apud FRAGA, 2010, p. 58) tece considerações motivadoras e mobilizadoras a respeito do desenvolvimento e busca por uma atitude interdisciplinar delineando algumas de suas características, quais sejam:

[...] uma atitude diante de alternativas para conhecer mais e melhor; atitude de espera ante os atos consumados, atitude de reciprocidade que impele à troca, que impele ao diálogo, atitude de humildade diante do próprio saber, atitude de perplexidade ante a possibilidade de desvendar novos saberes, atitude de desafio - desafio perante o novo, desafio de redimensionar o velho -, atitude de envolvimento e comprometimento com os projetos e com as pessoas neles envolvidas, atitude, pois de compromisso em construir sempre da melhor forma possível, atitude de responsabilidade, mas, sobretudo de alegria, de revelação, de encontro, enfim de vida. (FAZENDA, 2003 apud FRAGA, 2010, p. 58).

A compreensão de que promissoras ações interdisciplinares se iniciam sempre a partir da atitude é valorizada da mesma forma por Chamon (2011, p. 4). Entretanto esta autora ainda assevera que a interdisciplinaridade é anterior à atitude, estando presente também no âmago da própria existência humana. O brilho da interdisciplinaridade é visível na vida, que segundo a autora “é interdisciplinar”. Além disso, Chamon reforça que a interdisciplinaridade se faz presente igualmente desde a infância, sendo percebida tanto na "curiosidade infantil” quanto no "progresso das séries escolares”, por exemplo, na medida em que ocorre gradativamente a "multiplicação dos professores e com eles as disciplinas". Por fim, a autora coloca também o quanto “é curioso o fato da interdisciplinaridade teórica e a prática enfrentarem dificuldades de natureza totalmente distinta” e complementa afirmando que "talvez porque a primeira deva ser pensada, enquanto a última deve ser vivida” (ibid., p. 4).

Resgatando a questão do diálogo, dada sua importância enquanto condição sine qua non para se chegar à interdisciplinaridade, conta-se agora com auxílio de recursos metafóricos que por serem associativos, permitem uma compreensão hermenêutica. Ao se imaginar um rio com suas duas margens e uma ponte, considera-se o diálogo como sendo esta ponte. A ponte é o instrumento de travessia entre uma margem e outra do rio. As margens do rio representam os espaços ocupacionais dos diversos profissionais. O rio é aquele que separa os espaços ocupacionais. Quando o agir profissional, até então individual, caminha pela ponte na direção da outra margem, encontra o agir profissional do outro. E assim, ambos se encontram numa mesma margem do rio, significando que 
já houve anteriormente a superação de um possível primeiro obstáculo - a travessia pela ponte - ou seja, a intenção do diálogo foi instaurada e sua efetivação a partir deste momento, consistirá no segundo obstáculo a ser também superado. Para que esse diálogo possa ocorrer de forma eficaz e contínua é necessário estar aberto e disposto a partilhar conhecimentos, linguagens e conceitos específicos de cada área envolvida.

Portanto, a interdisciplinaridade não se pauta pelo preconceito, mas ao contrário pela abertura, “onde todo conhecimento é importante devendo ser fundamentada na intersubjetividade, num regime de copropriedade, de interação, onde é possível o diálogo, condição esta para que exista a interdisciplinaridade” (SAMPAIO et al., 2010, p. 82). Na interdisciplinaridade, tem-se "uma relação de reciprocidade, de mutualidade" o que viabiliza o diálogo entre as diferentes disciplinas. "Interdisciplinaridade é questão de atitude, uma atitude que impeça o estabelecimento de certa Ciência, em detrimento de outra” (SAMPAIO et al., 2010, p. 83).

A abertura ao diálogo é um sinal de que se pode caminhar na intenção da convergência das ações e também na direção de um projeto societário comum. Portanto, o diálogo seguido pela corresponsabilização e pela humildade, num contexto respeitoso de explicitação das diferenças e a não sobreposição de um saber sobre o outro leva a instauração de uma ação nova: aquela ação que era individual se transforma em interdisciplinar. E com isso, experimenta-se quão real é a fala de Fazenda (1979 apud SAMPAIO et al., 2010, p. 82) quando a autora afirma que “a interdisciplinaridade não se ensina, nem se aprende, simplesmente vive-se, exerce-se”.

Por outro lado, com relação ao amadurecimento profissional, percebe-se que o compartilhar ações com profissionais de formação distinta daquela que se escolheu para si só traz benefícios. O profissional enriquece sobremaneira sua prática, possibilitando uma intervenção ativa ou reflexiva mais segura, fortalecida e com visão ampliada. A situação citada acima se remete a uma metáfora: quando se percebe que a casa esta arrumada e organizada, tem-se mais clareza daquilo que falta e por isso, deve-se sair às ruas e buscar fora aquilo que falta dentro.

Os indícios de tal amadurecimento também são percebidos no aspecto coletivo, ou seja, quando o corpo teórico de uma determinada profissão está bem desenvolvido, no sentido de que expressa com exatidão informações sobre a origem da profissão, bem como justificativa consolidada de sua autoridade e habilidade na realização da ação que se propõe a executar na sociedade. 
Portanto, definidos os conceitos teórico-metodológicos de uma determinada profissão, dada a existência de clareza quanto ao objeto de cada uma delas, é hora de buscar parceiros que contribuam para aumentar o horizonte de percepção e de ação do profissional.

\section{CONTEXTUALIZANDO A PRÁTICA PEDAGÓGICA, INTERVENTIVA E DE PESQUISA}

Apesar de a questão interdisciplinar possuir apenas "10 anos no Sistema Nacional de Pós-Graduação, ela já possui massa crítica suficiente para se permitir uma auto avaliação, definindo melhor sua própria estrutura de organização, procedimentos e regulamentações” (BRASIL, 2010, p. 136). Portanto, tematizar a prática pedagógica, interventiva e de pesquisa no âmbito da interdisciplinaridade é algo procedente "e ainda, cientes da crescente importância da questão Multi e Interdisciplinar no ensino, na pesquisa, novos grupos de pesquisa e docentes qualificados devem ser estimulados a propor novos programas” (ibid., p. 142).

A formação imbuída de princípios interdisciplinares apresenta-se como essencial e quase que vital para a atualidade sob o risco das profissões de forma geral, fenecer dentro de seus próprios muros. Vive-se numa época de incentivo a articulação de áreas de conhecimento afins, demonstrando o quanto a questão da interdisciplinaridade faz parte do cotidiano de todo e qualquer profissional. O contrário, ou seja, a não articulação entre as áreas de conhecimento pode comprometer a condição da vida humana na medida em que a fragmentação excessiva, o enfoque exacerbado na especialidade acadêmica tende a isolar o homem que é, na sua essência, interdisciplinar, sendo também possuidor de necessidades interdisciplinares.

Segundo Severino (2010, p. 19-20) a prática interdisciplinar no âmbito do ensino adquire destaque de extrema relevância e se apresenta como crucial,

[...] dado o efeito multiplicador da ação pedagógica. A educação é, aliás, o exemplo dos mais evidentes, da necessidade de uma abordagem interdisciplinar, seja como objeto de conhecimento e de pesquisa, seja como espaço de intervenção sociocultural [...] Como formar o profissional e o cientista a não ser sob um enfoque interdisciplinar? É inevitável concluir que a autêntica iniciação à Ciência e à prática da pesquisa passa, de forma necessária, por uma metodologia vazada na interdisciplinaridade. (SEVERINO, 2010, p. 19-20) 
De acordo com Lenoir (2006, p. 3) "inúmeras publicações procuraram retraçar a evolução do conceito de interdisciplinaridade no plano científico e educacional numa perspectiva sócio-histórica. E nesta direção, alguns “abordam a questão de maneira mais global, outros a aproximam de um ponto de vista mais local ou em função de um domínio de aplicação particular” (ibid., p. 4). Esta realidade é compartilhada também pelas autoras Baptista e Rodrigues (1992, p. 119) ao afirmarem que:

A multidisciplinaridade na abordagem teórica tem em vista enriquecer o conhecimento com novas dimensões e permitir a percepção da característica total do conhecimento. E principalmente através de cursos interdisciplinares que a Pós-Graduação pode proporcionar uma maior abertura mental, desenvolvendo o poder de observação, de conhecimento e de crítica.

Nos ambientes acadêmicos, onde é dada ênfase na questão da interdisciplinaridade, existe um esforço na direção do fortalecimento da construção das identidades profissionais. Neste aspecto a autora Fazenda (2002, p. 11) afirma que “a interdisciplinaridade é uma nova atitude diante da questão do conhecimento, de abertura à compreensão de aspectos ocultos do ato de aprender e dos aparentemente expressos, colocando-os em questão”. E esta nova atitude é consolidada nos profissionais voltados a prática docente interdisciplinar, quando imbuída pela: "humildade, coerência, espera, respeito e desapego" (FAZENDA, 2002, p. 11). Considera-se também que a presença da “afetividade e da ousadia impelem às trocas intersubjetivas, às parcerias” (ibid., p. 12).

No campo da intervenção, a ênfase é igualmente sentida na medida em que situações sociais, políticas e econômicas exigem respostas que só podem ser dadas por parte de uma equipe interdisciplinar. Diante disso se compreende a necessidade da recorrência “à interdisciplinaridade em função da existência de outro método de análise do mundo e também em função de finalidades sociais porque cada uma das disciplinas científicas sozinhas não pode responder adequadamente às problemáticas altamente complexas” (LENOIR, 2006, p. 9).

Esta realidade é reforçada novamente por Lenoir (2006, p. 7) ao afirmar que a interdisciplinaridade possui vínculo direto com a intervenção do profissional no contexto diário de trabalho, portanto a interdisciplinaridade não diz respeito unicamente a uma “categoria de conhecimento, mas também a uma categoria de ação. [...] a interdisciplinaridade viu-se solicitada nesta segunda metade do século XX por forças não diretamente científicas, mas por forças ligadas à complexidade crescente da realidade social e das atividades sociais cotidianas” (LENOIR, 2006, p. 7). 
A importância da interdisciplinaridade apresenta-se também na esfera da pesquisa, produção e divulgação de conhecimentos adquiridos, sistematizados e construídos. Na medida em que se produzem conhecimentos interdisciplinares, via pesquisa ou estudos teóricos, os mesmos precisam ser comunicados através da linguagem escrita, oral e midiática para que haja o desencadeamento de ações coletivas que viabilizem novas propostas profissionais e novas reflexões.

Os conhecimentos produzidos pelo Serviço Social, enquanto uma especificidade das Ciências Humanas e Sociais não deve limitar-se à sua área de conhecimento, mas buscar uma produção que informe também estas ciências como um todo, especialmente aquelas mais afins com a atuação do Serviço Social buscando dar ênfase na transdisciplinaridade e na produção coletiva (BAPTISTA; RODRIGUES, 1992, p. 117).

É reconhecida a relevância da interdisciplinaridade na busca da produção de conhecimentos. Isso se verifica quando se analisa os eixos temáticos de pesquisas dentro da Coordenação de Aperfeiçoamento de Pessoal de Nível Superior (CAPES). A possibilidade de articular a produção dos conhecimentos com a intervenção na realidade social pautada nas ações interdisciplinares é muito comum (SILVA E SILVA et al., 2005). É interessante também verificar que o "recredenciamento obrigatório na CAPES tem oportunizado a redefinição do projeto acadêmico dos Programas e tem apontado uma maior preocupação pela perspectiva transdisciplinar da formação e da pesquisa, do pluralismo teórico-metodológico referenciado por uma Teoria Social” (BAPTISTA; RODRIGUES, 1992, p. 118).

Ainda no que tange à produção de conhecimento, se reconhece que nas Ciências Humanas, deve existir um contínuo caminhar na direção da interdisciplinaridade porque “toda conclusão obtida numa área fica como que incompleta, aberta, com 'encaixes' preparados para receber complementação de outra área” (SEVERINO, 2010, p. 19, grifo do autor).

A multidisciplinaridade na abordagem teórica tem em vista enriquecer o conhecimento com novas dimensões e permitir a percepção da característica total do conhecimento. E principalmente através de cursos interdisciplinares que a Pós-Graduação pode proporcionar uma maior abertura mental, desenvolvendo o poder de observação, de conhecimento e de crítica (BAPTISTA; RODRIGUES, 1992, p. 119).

A valorização da interdisciplinaridade se apresenta com o mesmo peso quando se busca analisar dados coletados numa pesquisa. A Análise por Triangulação de Métodos, por exemplo, consiste numa “estratégia de pesquisa que se apoia em métodos 
científicos testados e consagrados, servindo e adequando-se a determinadas realidades, com fundamentos interdisciplinares” (MINAYO et al., 2010, p. 71).

Mediante a certeza de que a interdisciplinaridade tem muito a contribuir no contexto da prática pedagógica, interventiva e de pesquisa é que se comunga da seguinte fala de Lenoir (2006):

[...] a interdisciplinaridade responde a duas grandes orientações distintas: por um lado, do ponto de vista epistemológico, a pesquisa de uma síntese conceitual, quer dizer, a pesquisa de uma unificação das ciências e a busca de unidade do saber, e, por outro lado a pesquisa de respostas operacionais às questões sociais ou tecnológicas pelo intermediário de abordagens instrumentais (ibid., p. 9).

Trabalhar, pensar e estudar interdisciplinarmente significa abrir-se a um diálogo respeitoso com os demais profissionais e estudantes que se colocam diante de si, com o objetivo de fortalecer e aprimorar o agir e o pensar que individualmente já se vinha realizando enquanto profissional pertencente a uma determinada área do saber, na certeza de que "os saberes são sempre marcados pela incompletude e insuficiência de intervenções, sendo que o diálogo entre as diferentes áreas pode ser um caminho para se consolidar as atitudes necessárias à interação” (FRAGA, 2010, p. 59).

A interdisciplinaridade, quando efetivamente plural, envolve não só o ensino propriamente dito, mas também a estratégia que favorece a comunicação de ideias, a articulação e o esforço conjunto em torno de assuntos correlatos no domínio do saber e no domínio da investigação, permitindo ampliar o âmbito do conhecimento e da prática. (BAPTISTA; RODRIGUES, 1992, p. 120).

\section{INTERDISCIPLINARIDADE E POLÍTICAS PÚBLICAS}

A Constituição Federal Brasileira datada de 1988, ao estabelecer no seu artigo $6^{\circ}$ que "são direitos sociais: a educação, a saúde, o trabalho, o lazer, a segurança, a previdência social, a proteção à maternidade e à infância, a assistência aos desamparados na forma desta Constituição” (BRASIL, 2004, p. 15), já aponta evidencias do quanto é necessária à articulação de várias políticas públicas e, consequentemente, de profissionais de diferentes formações para dar conta do acesso aos direitos estabelecidos em lei. Diante disso, está colocada, mesmo que implicitamente, a questão da interdisciplinaridade como via de acesso e estrada obrigatória pela qual os profissionais de diferentes formações precisam trilhar.

Como a práxis social é uma atividade política que pode mudar as relações econômicas, sociais e políticas, ela exige o desenvolvimento de ações integradas dos diferentes setores da sociedade, já que a 
solução dos problemas sociais não se constitui responsabilidade de uma área de saber, de determinada categoria profissional (SETUBAL, 2007, p. 65).

Portanto, percebe-se o quanto a questão da interdisciplinaridade se faz presente adquirindo status relevante e se justificando não somente por decorrência de questões sócio históricas, mas também e principalmente, por consequência das necessidades da atualidade representadas pelo percurso que as políticas públicas trilham na direção da descentralização com ênfase na sua municipalização.

Vê-se, por conseguinte que a interdisciplinaridade está intimamente ligada à questão da formação continuada, principalmente nos dias atuais quando por decorrência da mencionada municipalização da Assistência, o profissional de Serviço Social é chamado a ampliar seu espaço sócio ocupacional de forma a conter também “atividades relacionadas ao controle social, à implantação e orientação de conselhos de políticas públicas, à capacitação de conselheiros, à elaboração de planos e projetos sociais, ao acompanhamento e avaliação de políticas, programas e projetos” (IAMAMOTO, 2011, p. 207).

Assim sendo, levando-se em conta a conjuntura e apesar dela, fica clara a necessidade de consolidação da interlocução de distintos profissionais pela via da interdisciplinaridade, no sentido de responder às demandas das classes subalternas às quais, em sua maioria, usuárias das políticas sociais públicas.

É importante destacar que no contexto atual, as políticas públicas sofrem os impactos da crise do capital, à qual enfraquece o movimento de ampliação/efetivação das lutas por direitos, na medida em que o próprio Estado é capturado pelo capital. Neste sentido, a efetivação dos direitos via políticas públicas é atravessada por contradições e, consequentemente, o trabalho dos profissionais que nelas atuam também sofre estes impactos, e muitas vezes, o compromisso profissional com a efetivação dos direitos é frustrado por conta desta conjuntura. Por isso, no âmbito da intervenção interdisciplinar, é importante construir "um cenário de discussão sobre responsabilidades e possibilidades na construção de uma proposta ético-política e profissional que não fragmente o sujeito usuário da Política de Assistência Social” (PARÂMETROS..., 2009, p. 27).

"O trabalho interdisciplinar em equipe deve ser orientado pela perspectiva de totalidade, com vistas a situar o indivíduo nas relações sociais que tem papel determinante nas suas condições de vida” (ibid., p. 24-25). E isso é muito importante Serv. Soc. \& Saúde, Campinas, SP v. 11, n. 1 (13), p. 67-98 jan./ jun. 2012 ISSN 1676-6806 
porque o neoliberalismo também traz repercussões nas ações interdisciplinares, na medida em que se apresenta como gerador do crescimento do desemprego, do trabalho precário e informal, “da desmobilização do movimento social e sindical, do desmonte dos direitos sociais e da elevação dos níveis de pobreza, influenciando diretamente nas relações de trabalho, na questão social, nas relações sociais e consequentemente no conteúdo das profissões” (CARVALHO; SILVA E SILVA, 2005, p. 135-136).

A compreensão da Política Social, “como campo da prática profissional por excelência, lugar onde ocorre a constituição de direitos e o reconhecimento da cidadania, mas que seguramente, não representa campo exclusivo do assistente social” (SPOSATI, 2007, p. 21) permite o rompimento com a univocidade interventiva e teórica, ao mesmo tempo em que amplia para o assistente social as possibilidades de interlocução com os demais profissionais que também atuam dentro deste contexto.

Especificamente no âmbito da Política Pública de Assistência Social, diversos são os profissionais que realizam sua intervenção contextualizada no Sistema Único da Assistência Social (SUAS), dos quais se destaca os assistentes sociais, os psicólogos, pedagogos dentre outros. Desses, todos podem contribuir para que sejam criadas ações coletivas visando o enfrentamento das diversas expressões da questão social. Desta forma, é possível caminhar na reafirmação de "um projeto ético e sócio-político de uma nova sociedade que assegure a divisão equitativa da riqueza socialmente produzida" (PARÂMETROS..., 2009, p. 24). A atuação interdisciplinar requer construir uma prática político-
profissional que possa dialogar sobre pontos de vistas diferentes,
aceitar confrontos de diferentes abordagens, tomar decisões que
decorram de posturas éticas e políticas pautadas nos princípios e
valores estabelecidos nos Códigos de Ética Profissional. A
interdisciplinaridade, que surge no processo coletivo de trabalho,
demanda uma atitude ante a formação e conhecimento, que se
evidencia no reconhecimento das competências, atribuições,
habilidades, possibilidades e limites das disciplinas, dos sujeitos, do
reconhecimento da necessidade de diálogo profissional e cooperação.
(PARÂMETROS..., 2009, p. 26).

Portanto, não obstante as principais profissões hoje atuantes no SUAS, possuírem bagagens teórico-políticas diferenciadas, isso não invalida o estabelecimento de um diálogo entre elas, onde através de uma reflexão crítica é possível alcançar a “compreensão dos aspectos objetivos e subjetivos inerentes ao convívio e à formação do indivíduo, da coletividade e das circunstâncias que envolvem as diversas situações que se apresentam ao trabalho profissional” (PARÂMETROS..., 2009, p. 27). 
Segundo Raichelis (2011), o diálogo entre os diversos profissionais que compõem o Sistema Único da Assistência Social é fundamental para superar a cultura do pragmatismo e o produtivismo quantificado do trabalho, ao mesmo tempo em que propicia uma leitura crítica da realidade e desafia a capacidade analítica e propositiva dos profissionais. A autora defende também que além de atitudes interdisciplinares situadas no âmbito profissional, é imprescindível ainda no contexto das Políticas Públicas a criação de mecanismos de gestão interdisciplinar.

A intervenção interdisciplinar "requer interface com as Políticas da Saúde, Previdência, Educação, Trabalho, Lazer, Meio Ambiente, Comunicação Social, Segurança e Habitação, na perspectiva de mediar o acesso dos (as) cidadãos (ãs) aos direitos sociais” (PARÂMETROS..., 2009, p. 24).

As abordagens das profissões podem assegurar uma intervenção interdisciplinar capaz de responder a demandas individuais e coletivas, com vistas a defender a construção de uma sociedade livre de todas as formas de violência e exploração de classe, gênero, etnia e orientação sexual (PARÂMETROS..., 2009, p. 24).

\section{FORMAÇÃO CONTINUADA E INTERVENÇÃO INTERDISCIPLINAR DO SERVIÇO SOCIAL}

Observa-se que na década de 1960, o período é marcado pelo crescimento das reflexões em torno da defesa e "necessidade se atribuir um enfoque interdisciplinar à formação e à intervenção profissional em 1970 e 1980, este debate cresceu e ganhou maiores proporções na década de 1990, adquirindo hoje ampla repercussão” (ELY, 2003, p. 114).

Ao situar o Serviço Social, Bourguignon (2007, p. 48) defende que "em sua trajetória histórica, a profissão, ao construir e reconstruir um legado teórico, estabelece diálogo crítico com outras áreas do conhecimento”. Na direção deste desenvolvimento da capacidade de interlocução interdisciplinar, um fato histórico significativo, ocorrido nas últimas décadas, ilustra a fala da autora. A narrativa é de Sposati (2007, p. 17-18) que ao contextualizar o Serviço Social nas décadas de 1980 e 1990, afirma que os assistentes sociais se lançaram num exaustivo empenho para:

[...] fortalecer a base científico-profissional difundida através do processo de desconstrução e reconstrução crítica da profissão e de seu exercício, fundando-se no aporte sócio histórico da análise do real [...]. Este processo teve como mérito o fortalecimento da pesquisa para os assistentes sociais. O vínculo entre a produção do conhecimento e 
este processo histórico gerou a capacidade de interlocução entre pesquisadores provindos do Serviço Social com aqueles ligados a outros saberes. Ampliou-se, portanto, a inserção e a interlocução interdisciplinar, e com elas, a construção do reconhecimento científico desta "nova" perspectiva de análise do real (SPOSATI, 2007, p. 1718 , grifo da autora).

Por consequência, desse exaustivo empenho verifica-se conforme afirma Lara (2007, p. 76-77) que, em meados da década de 80, a categoria dos assistentes sociais

[...] começou a contribuir e a responder pela produção do conhecimento que dão sustentação segura à prática profissional. Hoje podemos afirmar que contribuímos com significativos trabalhos de pesquisa nas mais diversas subáreas das ciências sociais (LARA, 2007, p. 76-77).

Segundo Guerra (2005), a dimensão ético-política presente no ensino, durante a graduação do Serviço Social, favorece uma formação que possibilite uma intervenção interdisciplinar. Neste sentido, a autora coloca que o ensino da prática:

[...] deve permitir que se desenvolvam valores coletivos (sociocêntricos) e práticas democráticas, em detrimento de valores individualistas e práticas autoritárias. Deve-se preocupar em formar atitudes, desenvolver interesses, habilitar e capacitar os estudantes para vislumbrar as formas de articular a prática de formação a outras práticas profissionais, tecendo relações interdisciplinares [...] (Ibid., 2005, p. 151).

Posterior a graduação, no momento em que o profissional estiver plenamente envolvido com seu projeto ético-político, também irá se deparar com realidades interdisciplinares. Como “não acreditamos que se faça um projeto ético-político profissional sem o reconhecimento claro e profundo das diferenças existentes, a possibilidade de aprender a conviver com as diversidades é o caminho para o exercício ético e político diferenciado” (SARMENTO, 2011, p. 219). Portanto, a necessidade de trabalhar no âmbito da interdisciplinaridade se faz presente no cotidiano profissional.

É importante observar que este projeto é coletivamente partilhado na medida em que outros profissionais também contribuem para que o indivíduo em situação de vulnerabilidade social tenha seu direito respeitado e acessado dentro da Política Pública de que necessita naquele período de sua existência, podendo ser uma necessidade de saúde, educação, habitação, renda, trabalho.

Quando se busca uma intervenção interdisciplinar, através da construção de ações coletivas junto com profissionais, advindos de diferentes formações acadêmicas, 
vendo-os como interlocutores privilegiados, imprescindíveis, criam-se maiores possibilidades de enfrentamento dos dilemas que retratam a vulnerabilidade social. E em decorrência disso, além do Serviço Social ampliar seu universo interventivo pode também favorecer processos relacionais pautados na transferência recíproca de conhecimentos, oportunizando espaços de socialização “com as demais áreas do conhecimento as suas reais especificidades e habilidades e, dependendo da competência do profissional, até romper com o 'preconceito’ que estas áreas historicamente atribuem à formação do assistente social” (ELY, 2003, p. 116, grifo da autora).

Ademais, quando a necessidade da formação continuada se colocar diante do profissional como desafio e condição no avançar de sua prática pedagógica, interventiva ou de pesquisa, mais uma vez o assistente social se encontrará diante da interdisciplinaridade. Portanto, compete ao assistente social "privilegiar o diálogo da profissão com outros campos e saberes profissionais, favorecendo a possibilidade de dar repostas às demandas socialmente apresentadas” (CARVALHO; SILVA E SILVA, 2005, p. 135).

O Serviço Social, ao buscar novas formas de executar seu trabalho, direciona seu envolvimento na ação interdisciplinar, compartilhando um espaço de troca mútua entre as especificidades do conhecimento e ultrapassando, no atendimento da complexidade das suas demandas, os limites de sua especialidade (ELY, 2003, p. 115).

Com o surgimento da pós-graduação também vem sendo construído “um espaço privilegiado de interlocução e diálogo do Serviço Social com as diferentes áreas do saber e entre diferentes tendências teórico-metodológicas que estão presentes no debate profissional” (YAZBEK; SILVA E SILVA, 2005, p. 29). A emergência destes espaços de "especialização interativa permite igualmente o diálogo de conceitos o que mostra que pesquisadores de áreas diferentes podem ser tão competentes na análise de um estudo quanto especialistas no ramo” (SPOSATI, 2007, p. 17).

O legado da interdisciplinaridade traz como consequência uma maturidade intelectual para a profissão "evidenciada pela sua produção teórica e capacidade de diálogo crítico, com diferentes áreas de conhecimento das ciências sociais e humanas” (BOURGUIGNON, 2007, p. 50). Portanto, são inúmeros os resultados positivos que podem ser imputados à interdisciplinaridade no âmbito do Serviço Social.

Algumas das consequências positivas deste trabalhar interdisciplinarmente situase na compreensão da importância do outro profissional de formação distinta como colaborador para alcance de objetivos comuns com muito mais possibilidade de êxito do Serv. Soc. \& Saúde, Campinas, SP v. 11, n. 1 (13), p. 67-98 jan./ jun. 2012 ISSN 1676-6806 
que se trabalhasse individualmente, assim as situações que demandam intervenção seriam melhor cercadas dentro da dinâmica interdisciplinar. Afinal, diante da propalada agudização da questão social é inconcebível que isoladamente enquanto "sujeito solitário" o assistente social se constitua como única resposta "para atender a tantas demandas postas no cotidiano”. Por tanto é imprescindível "o sujeito coletivo e a superação da perspectiva do fazer profissional do sujeito solitário” (FRAGA, 2010, p. 59).

Há necessidade de estratégia de ação na medida em que o Serviço Social se volta para o conhecimento da realidade social, política e econômica - contexto onde se gestam as questões sociais - o estudo de seu objeto científico requer o conhecimento substantivo de outras áreas e habilitação em técnicas especializadas. Daí a necessidade da formação de equipes de pesquisa interdisciplinar, que possibilitem uma pluralidade e diversificação de abordagens, no sentido da verticalização dos conhecimentos sobre uma temática (BAPTISTA; RODRIGUES, 1992, p. 132).

A relevância da abordagem da interdisciplinaridade e do sujeito coletivo é reforçada também pelas autoras Baptista e Rodrigues (1992). Segundo elas a não preocupação com a questão interdisciplinar representa um problema para o Serviço Social, na medida em que a complexidade das situações com as quais a profissão se defronta não são possíveis de serem decodificadas sob um único ângulo do olhar. Para as autoras, uma intervenção que traz melhores resultados é aquela que está respaldada por enfoques interdisciplinares porque "só com explicações que abordem os diferentes determinantes das relações da sociedade é que se pode compreender as possibilidades de abertura para a ação, a sua viabilidade e suas possíveis consequências” (ibid., p. 131).

A ação que passa pela perspectiva interdisciplinar proporciona a cada profissional, enquanto pessoa, questionar, opinar, discutir, atuar com relação à determinada ação. Assim o profissional não buscará limitar seu espaço de ação fragmentando a questão, numa atitude de exclusividade, mas o ampliará numa perspectiva conjunta, visualizando a totalidade da questão e, principalmente, chegando à economia de ação que não significa praticar menos, mas racionalizar e socializar a ação (MARQUES; RAMALHO, 2010, p. 68, grifo das autoras).

No documento intitulado Parâmetros para Atuação de Assistentes Sociais na Política de Assistência Social, elaborado pelo Conselho Federal de Serviço Social (2009, p. 28), interdisciplinaridade não significa negligenciar responsabilidades individuais e competências, mas buscar "identificar papeis, atribuições, de modo a 
estabelecer objetivamente quem dentro da equipe multidisciplinar, encarrega-se de determinadas tarefas”.

A construção do trabalho interdisciplinar impõe aos (às) profissionais a realização permanente de reuniões de planejamento e debates conjuntos a fim de estabelecer as particularidades da intervenção profissional, bem como definir competências e habilidades profissionais em função das demandas sociais e da especificidade do trabalho (PARÂMETROS..., 2009, p. 28).

Logo, deve-se descartar a compreensão de que com a interdisciplinaridade correse o risco de anular a contribuição que cada área ou disciplina em particular pode oferecer. Neste caminho, Sampaio et at. (2010) destaca que é possível vislumbrar novas formas de entendimento da interdisciplinaridade. Para as autoras, interdisciplinaridade enquanto conhecimento assemelha-se a "uma lógica de descoberta, uma abertura recíproca, uma comunicação entre os domínios do Saber” (ibid., p. 83).

Substancial também é a consideração que as mesmas autoras fazem a respeito da ação interdisciplinar: a interdisciplinaridade enquanto atitude leva o profissional a "reconhecer os limites de seu saber para receber contribuições de outras disciplinas” (Ibid.; p. 83). Assim, “toda Ciência seria complementada por outra e a separação entre as Ciências seria substituída por objetivos mútuos onde cada disciplina daria sua contribuição, preservando a integridade de seus métodos e conceitos” (SAMPAIO et at., 2010, p. 83).

Não obstante a divisão e fragmentação de saberes permear constantemente a intervenção das diversas categorias profissionais no espaço sócio ocupacional onde estão localizados, ainda assim este espaço apresenta-se como território privilegiado para a realização de articulação entre as ações, pois se considera que a busca pela qualidade na intervenção parte a priori, justamente, deste contexto cotidiano.

A dinâmica das intervenções realizadas pelo assistente social forja a necessidade de inscrevê-las num delimitado espaço geográfico onde se localiza a rede de proteção social, ou seja, demais organizações governamentais e não governamentais que prestam serviços na área da saúde, da assistência social, da educação, da habitação dentre outras. Nesse sentido, trabalhar interdisciplinarmente significa também abrir-se a um diálogo respeitoso com os demais profissionais que atuam na mesma área de abrangência de sua respectiva ação, com o objetivo de fortalecer, aprimorar e complementar o trabalho do assistente social. 
Portanto "dentro" e "fora de casa”, o assistente social é impelido a buscar respaldo no trabalho interdisciplinar, é por isso que, o Código de Ética do Assistente Social, no capítulo III, artigo10, alínea “d” e “e”, captou com precisão a importância do envolvimento do profissional com questões relacionadas à interdisciplinaridade tanto no que se refere à formação continuada e à atuação prática quanto à abertura ao diálogo e convivência respeitosa. "O código que contém em seu pórtico a instituição de alguns princípios fundamentais da ordem democrática, aplicados à inserção da categoria profissional na sociedade” (SIMÕES, 2010, p. 542), apresenta a seguinte redação: “Capítulo III Das Relações dos Assistentes Sociais e outros profissionais, Artigo 10 São deveres do assistente social: [...] d) incentivar, sempre que possível, a prática profissional interdisciplinar; e) respeitar as normas e princípios éticos das outras profissões; [...]” (CONSELHO FEDERAL DE SERVIÇO SOCIAL, 2007, p. 26-27).

A participação em equipe interdisciplinar apresentada como dever a
ser cumprido sempre que se apresentarem possibilidades, relaciona-se
com um dos princípios fundamentais deste Código, referente ao
compromisso com a qualidade dos serviços prestados à população e
com o aprimoramento intelectual, na perspectiva da competência
profissional (ELY, 2003, p. 115).

Na mesma direção, a Associação Brasileira de Ensino e Pesquisa em Serviço Social (ABEPSS) também incentiva a articulação do Serviço Social com áreas de conhecimento afins ao demonstrar o quanto esta questão faz parte do cotidiano do assistente social, reforçando que a consolidação desta interlocução possibilita dar visibilidade ao Serviço Social, da mesma forma em que contribui para responder às demandas da sociedade brasileira. É considerado como importante para este órgão sua participação "na organização de eventos nacionais da área de educação, no sentido de estabelecer interlocução com outras áreas, tendo como perspectiva interferir na construção e implementação do programa nacional de educação, em contraponto ao Plano Nacional Governamental” (POLÍTICA..., 2004, p. 170-171).

E ainda, reforçando o incentivo na direção da interdisciplinaridade, as recomendações técnicas previstas no já mencionado documento intitulado Parâmetros para Atuação de Assistentes Sociais na Política de Assistência Social, “indicam a definição de modalidades interventivas que priorizam abordagens coletivas, ações comunitárias e realização de estudos voltados ao aprimoramento dos serviços” (SILVEIRA, 2009, p. 357). 
Numa equipe interdisciplinar, é esperado do Serviço Social uma intervenção que lhe seja própria, da mesma forma como se espera isso dos demais técnicos, porém sempre de forma participativa. Neste sentido, é desejável que as ações se pautem “numa postura político-ideológica vinculada ao processo de conscientização e de organização buscando contribuir com os conhecimentos técnicos científicos de sua disciplina, estudo e superação de determinadas situações” (MARQUES; RAMALHO, 2010, p. 68).

\section{DESAFIOS}

No V Plano Nacional de Pós-Graduação (PNPG 2011-2020) lê-se que é necessário “levar em consideração que a Área Interdisciplinar, além de ser uma das mais novas dentre todas as outras, enfrenta as dificuldades de quem se aventura fora das áreas disciplinares tradicionais e, portanto, necessita romper com certos paradigmas” (BRASIL, 2010, p. 138). Neste sentido, não obstante o alcance dos incontáveis resultados positivos que a interdisciplinaridade pode trazer, cabe ressaltar que um dos desafios a sua concretização perpassa pela compreensão de que:

[...] o alcance destes objetivos não se faz mecanicamente, bastando para isso que se tenha profissionais de diferentes áreas. Para que isso ocorra, é preciso que a abordagem dos profissionais não se faça de forma estanque e que não parta de preconceitos quanto à especificidade de cada área. O importante é perceber que a realidade é uma totalidade, ainda que parcial, com uma dinâmica própria, inserida em outras totalidades que a determinam e das quais compõe uma dimensão. Neste sentido, a contribuição das outras disciplinas para o conhecimento específico de uma determinada profissão tem como condição que estas tenham em vista aquela totalidade parcial e as suas relações (BAPTISTA; RODRIGUES, 1992, p. 119).

Outro desafio é entender que na vida cotidiana, é comum se deparar com aquele ou com aquilo que é diferente, que é específico. E, apesar de tais constatações, nem por isso se deixa de viver, se deixa de conviver com estas realidades ou com estas pessoas. Existe um reencontro e uma complementação destas realidades no dia a dia da vida de todas as pessoas de forma contraditória e dialética. O mesmo ocorre com a interdisciplinaridade, que não exige a eliminação das diferenças para poder se consolidar, se estabelecer neste ou naquele ambiente. E o mais importante, segundo Severino (2010, p. 20), esta convivência entre os diferentes não significa o predomínio de um sobre o outro, mas sim “correlação e reciprocidade de significação" onde 
prevalece a "autonomia bem definida de cada um e a segurança da própria identidade assumida e cultivada” (ibid., p. 21).

Identifica-se mais um desafio para que a interdisciplinaridade se efetive. Este diz respeito à superação de algumas barreiras pertinentes ao processo de sua consolidação nos mais diversos ambientes. Segundo Fazenda (1979 apud SAMPAIO et al., 2010, p. 84) é necessário "que as instituições abandonem seus hábitos cristalizados e partam em busca de novos objetivos e, que as Ciências compreendam as limitações de seus aportes”. Soma-se a isso, outro desafio, também demandatário de superação, e que exige um esforço para que se caminhe a passos mais largos rumo à interdisciplinaridade. Trata-se das barreiras que as pessoas individualmente ou enquanto categorias profissionais constroem ao redor de si. E vários motivos podem levar a isso, como por exemplo, questões pessoais, sociais, culturais dentre outras. Portanto, a concretização da interdisciplinaridade esbarra na:

[...] trajetória histórica de cada profissão, a postura ideológica, pessoal e profissional de cada elemento da equipe e as relações sociais, que implicam a conquista de espaço e a competitividade, originárias da própria estrutura social, onde está presente a variável da divisão social do trabalho, vinculada ao modelo capitalista dependente (SAMPAIO et al., 2010, p. 93).

Não obstante a importância e urgência da implantação e implementação de ações interdisciplinares nos contextos sócio ocupacionais, reforçadas pelas necessidades dos tempos atuais, é relevante ter presente o que Iamamoto (2004) esclarece sobre postura vigilante. Para a autora, isso é considerado como outro desafio. Isso significa que tanto os assistentes sociais como os profissionais de formação distinta que buscam pautar suas intervenções na dimensão interdisciplinar, devem assumir um compromisso com suas respectivas legislações as quais elucidam as competências privativas de cada um, “observância de princípios e comportamentos ético-morais, disciplinados pelos órgãos de defesa e regulamentação das profissões” (ibid., p. 70). E ainda, caso os demais profissionais tiverem um Projeto Ético-Político próprio, como tem o Serviço Social, é necessário também adequar as ações interdisciplinares desenvolvidas, bem como os objetivos destas ações àquilo que está regulamentado nos distintos projetos profissionais. Portanto, “a defesa da formação especializada de nível universitário” (IAMAMOTO, 2004, p. 70) não pode ser perdida de vista no contexto interdisciplinar.

Ainda segundo Iamamoto (2004), é preciso ter presente também que os usuários dos serviços prestados por equipe interdisciplinar, têm direito a receber por parte do 
assistente social, caso este venha a compor a equipe interdisciplinar, atendimento de um profissional "dotado de competência técnico-científica e ético-política que respeite às necessidades e interesses sociais dos usuários, contribuindo para a efetivação dos direitos sociais” (IAMAMOTO, 70). Portanto, a autora defende que os deveres que os assistentes sociais têm diante daqueles que procuram pelos seus serviços, os quais estão regulamentados no Código de Ética Profissional datado de 1993, na Lei nº 8. 662/93 de Regulamentação da Profissão de Serviço Social, nas Diretrizes Curriculares para a Formação Profissional em Serviço Social propostas pela ABEPSS em 1996 e normatizados no Projeto Ético-Político da profissão, devem ser motivo de atenção e de postura vigilante independente do contexto sócio ocupacional se configurar como disciplinar ou interdisciplinar.

Além destas considerações e com relação a este mesmo desafio expresso na necessidade de se assumir uma postura vigilante, o documento Parâmetros para atuação de Assistentes Sociais na Política de Assistência Social (2009, p. 25-26) advoga que:

Balizados pelos seus códigos de Ética, Leis de Regulamentação e Diretrizes Curriculares de formação profissional, os (as) profissionais podem instituir parâmetros de intervenção que se pautem pelo compartilhamento das atividades, convivência não conflituosa das diferentes abordagens teórico-metodológicas que estabelecem o que é próprio e específico a cada profissional na realização de estudos socioeconômicos, visitas domiciliares, abordagens individuais, grupais e coletivas.

Nesta direção, o V Plano Nacional de Pós-Graduação (PNPG, 2011-2020) comunga dos mesmos princípios e preocupações ao expressar que:

[...] não há experiência Inter ou Multidisciplinar bem-sucedida, sem a experiência ou sem um conhecimento Disciplinar forte - então, se não há base e lastro Disciplinar, o Programa - que por vocação e natureza deve ser voltado para a excelência e gerar um adicional de saber deverá ser instado a mudar sua proposta e estrutura ou mesmo ser descredenciado (BRASIL, 2010, p. 141-142).

Por fim, como a incorporação da interdisciplinaridade na ambiência acadêmica e sócio ocupacional possibilita articulação de saberes técnicos, onde especialistas ao compartilhar objetivos comuns propiciam ganhos para a equipe docente e discente, bem como população em situação de vulnerabilidade, tem-se outro desafio. Esse considera a importância da instituição de espaços de discussão e reflexão dos aportes teóricos e metodológicos que fundamentam a intervenção e possibilitem melhorias permanentes, 
considerando as especialidades e necessidades de todos os envolvidos sejam eles destinadores ou destinatários das ações realizadas (PARÂMETROS..., 2009).

Diante dos inúmeros desafios sinalizados, bem como de outros que certamente extrapolaram os limites da apreensão que se buscou realizar nesta análise, mas que potencialmente se constituem como elementos impeditivos na evolução do processo de interlocução entre as diferentes áreas do saber, é mister considerar que aprender a conviver com a interdisciplinaridade não é somente uma recomendação em nível ético a ser dada ao profissional de Serviço Social e aos profissionais de forma geral. É antes de tudo uma exortação antropológica com valência universal, que contem em si os princípios fertilizadores capazes de gerar espaços ocupacionais e acadêmicos novos, estratégias de ações novas e profissionais novos porque "hoje talvez mais que no passado, os homens dão-se conta de que estão ligados por um destino comum, que há de ser construído conjuntamente, se se quiser evitar a catástrofe para todos” (WOJTYLA, 2002, p. 105).

\section{CONSIDERAÇÕES FINAIS}

Conclui-se na certeza de que as oportunidades para se construir diálogos interdisciplinares devem ser aproveitadas ao máximo, principalmente porque isso significa reconhecer que somente a partir da atuação interdisciplinar se pode chegar à resolução de problemas estruturais que atingem a sociedade como um todo e focá-los não de forma fragmentada, mas na sua totalidade, na sua dimensão coletiva, que por outra via senão da interdisciplinaridade, não é possível de ser enfrentado. Enquanto não se considerar a importância da interdisciplinaridade, a questão social, para citar apenas um exemplo, continuará sendo tratada de forma parcial, sendo focada apenas em algumas de suas diversas expressões.

Portanto, espera-se com esta reflexão, cujo propósito não foi quantificar diferentes pontos de vista e ideias sobre o assunto, reforçar a urgência e importância de se pensar e agir interdisciplinarmente. Principalmente porque todo o agir e pensar interdisciplinar produz reflexos na realidade podendo contribuir na construção dos destinos da humanidade. 


\section{REFERÊNCIAS}

BAPTISTA, M.V.; RODRIGUES, M.L. A formação pós-graduada - Stricto Sensu - em Serviço Social: Papel da pós-graduação na formação profissional e desenvolvimento do Serviço Social. In: Cadernos ABESS-CEDEPSS, v. -, n. 5, maio. p. 108-134, 1992.

BOURGUIGNON, J. A. A particularidade histórica da pesquisa no Serviço Social. Katálysis, Florianópolis: EDUFSC, v.10, n. especial. p. 46-54, 2007.

BRASIL. Ministério do Desenvolvimento Social e Combate à Fome. Secretaria Nacional de Assistência Social. Política Nacional de Assistência Social. Brasília, DF, 2004.

BRASIL. Ministério da Educação. V Plano Nacional de Pós-Graduação - PNPG 2011-2020. Coordenação de Aperfeiçoamento de Pessoal de Nível Superior (CAPES). Brasília, DF, 2010. Disponível em: <http://www.capes.gov.br/sobre-a-capes/planonacional-de-pos-graduacao>. Acesso em: 07 fev. 2012.

BUARQUE DE HOLANDA, A. Dicionário da Língua Portuguesa. Curitiba: Positivo, 2010.

CARVALHO, D. B. B.; SILVA E SILVA, M. O. da. Conclusão. In:

(Orgs.). Serviço Social, Pós-Graduação e Produção de Conhecimento no Brasil. São Paulo: Cortez, 2005. p. 133-138.

CHAMON, E. M. Q. de O. Apresentação. In: (Org.). Gestão de Organizações

Públicas e Privadas: uma abordagem interdisciplinar. Rio de Janeiro: Brasport, 2007. p. VII-IX.

CHAMON, E. M. Q. de O. Memorial. São José dos Campos/SP: [s.n], 2011.

CONSELHO FEDERAL DE SERVIÇO SOCIAL. Código de Ética do Assistente Social. Lei $n^{0}$ 8.662/93 de regulamentação da profissão. Brasília: Teixeira Gráfica e Editora Ltda, 2007.

CUNHA, J.R. Epistemologia e Modernidade. O Positivismo: Comte. Revista FGV Direito. Rio de Janeiro, 2008. Disponível em: http://academico.direitorio.fgv.br/wiki/Epistemologia_e_Modernidade. Acesso em: 04 out. 2011.

ELY, F. R. Serviço Social e Interdisciplinaridade. Katálysis, Florianópolis: EDUFSc, v. 6, n. 1, p.113-117, jan./jun. 2003.

FAZENDA, I.C.A. (Org). Dicionário em construção: interdisciplinaridade. São Paulo: Cortez, 2002. 
FRAGA, C. K. A atitude investigativa no trabalho do assistente social. Serviço Social \& Sociedade, São Paulo, v. 31, n. 101. p. 40-64, 2010.

GUERRA, Y. O potencial do ensino teórico-prático no novo currículo: elementos para o debate. Katálysis. Florianópolis: EDUFSC, v.8, n. 2, p.147-154, jul./dez. 2005.

IAMAMOTO, M. V. Reforma do Ensino Superior e Serviço Social. Temporalis, Goiás, v.1, n. 1, p. 35-79, reimpressão jul. 2004.

IAMAMOTO, M. V. Serviço Social em Tempo de Capital Fetiche. São Paulo: Cortez, 2011.

LARA, R. Pesquisa e Serviço Social: da concepção burguesa de ciências sociais à perspectiva ontológica. Katálysis. Florianópolis: EDUFSC, v.10, n. especial. p.73-82, 2007.

LENOIR, Y. Três interpretações da perspectiva interdisciplinar em educação em função de três tradições culturais distintas. Revista E-Curriculum, PUCSP, São Paulo, vol. 1, nº 1, 2006. Disponível em: http://www.pucsp.br/ecurriculum. Acesso em: 29 set. 2011.

MARQUES, M.T.C.; RAMALHO, M.P. Os Movimentos Ecológicos e a Interdisciplinaridade. In: SÁ, J. M. de (Org.). Serviço Social e Interdisciplinaridade: Dos fundamentos filosóficos à prática interdisciplinar no Ensino, Pesquisa e Extensão. São Paulo: Cortez, 2010. p. 59-75.

MINAYO, M. C. S. et al. Métodos, técnicas e relações em triangulação. In: MINAYO, M. C. S.; ASSIS, S. G.; SOUZA, E.R. (Orgs.). Avaliação por triangulação de métodos: Abordagem de Programas Sociais. Rio de Janeiro: Fiocruz, 2010. p. 71-103.

PARÂMETROS para atuação de Assistentes Sociais na Política de Assistência Social. Conselho Federal de Serviço Social - CFESS, Brasília: [s.n.], 2009. (Série: Trabalho e Projeto Profissional nas Políticas Sociais).

POLÍTICA de Ensino Superior no Brasil: A regulamentação da LDB e as implicações para o Serviço Social - Relatório Final - ABEPSS, CFESS, ENESSO. Temporalis, Goiás, v.1, n. 1, p.165-179, reimpressão jul. 2004.

RAICHELIS, R. O lugar da Política de Assistência Social na Seguridade Social e o compromisso do Assistente Social frente às novas demandas. In: Encontro Regional de Seguridade e Controle Social, out. 2011, São José dos Campos/SP. (Anotações).

ROEHE, M.V. Uma abordagem fenomenológica-existencial para a questão do conhecimento em psicologia. Revista Estudos de Psicologia, UFRN, Rio Grande do Norte, Vol. 11, $\mathrm{n}^{\mathrm{O}} \quad 2,2006 . \quad$ Disponível em: http://redalyc.uaemex.mx/pdf/261/26111204.pdf. Acesso em: 05 out. 2011. Serv. Soc. \& Saúde, Campinas, SP v. 11, n. 1 (13), p. 67-98 jan./ jun. 2012 ISSN 1676-6806 
SÁ, J. M. de. Apresentação. In: SÁ, J. M. de. (Org.). Serviço Social e Interdisciplinaridade: Dos fundamentos filosóficos à prática interdisciplinar no Ensino, Pesquisa e Extensão. São Paulo: Cortez, 2010. p. 7-10.

SÁ, J. M. de. Especialização versus interdisciplinaridade: uma proposta alternativa. In: SÁ, J. M. de. (Org.). Serviço Social e Interdisciplinaridade: Dos fundamentos filosóficos à prática interdisciplinar no Ensino, Pesquisa e Extensão. São Paulo: Cortez, 2010. p. 23-58.

SAMPAIO, C.C. et al. Interdisciplinaridade em questão: Análise de uma política de saúde voltada à mulher. In: SÁ, J. L. M. de (Org.). Serviço Social e Interdisciplinaridade: Dos fundamentos filosóficos à prática interdisciplinar no Ensino, Pesquisa e Extensão. São Paulo: Cortez, 2010. p. 77-95. SARMENTO, H. B. de M. Ética e Serviço Social: fundamentos e contradições. Katálysis, Florianópolis: Edufsc, v.14, n. 2, p. 210-221, jul./dez. 2011. SETUBAL, A. A. Desafios à pesquisa no Serviço Social: da formação acadêmica à prática profissional, Katálysis. Florianópolis: EDUFSC, v.10, n. especial, p. 64-72, 2007.

SEVERINO, A. J. Subsídios para uma reflexão sobre novos caminhos da interdisciplinaridade. In: SÁ, J. M. de (Org.). Serviço Social e Interdisciplinaridade: Dos fundamentos filosóficos à prática interdisciplinar no Ensino, Pesquisa e Extensão. São Paulo: Cortez, 2010. p. 11-21.

SILVA E SILVA, M. O. da et al. A pesquisa, a produção e a divulgação de conhecimento dos programas de Pós-Graduação na área de Serviço Social. In: CARVAlHO, D. B. B.; SILVA E SILVA, M. O. da (Orgs.). Serviço Social, Pós-Graduação e Produção de Conhecimento no Brasil. São Paulo: Cortez, 2005. p. $69-131$.

SILVEIRA, J. I. Sistema Único de Assistência Social: institucionalidade e processos interventivos. Serviço Social \& Sociedade, São Paulo, v. 30, n. 105, p. 335-361, 2009. SIMÕES, C. Curso de Direito do Serviço Social. São Paulo: Cortez, 2010. SPOSATI, A. Pesquisa e produção de conhecimento no campo do Serviço Social. Katálysis, Florianópolis: EDUFSC, v.10, n. especial, p.15-25, 2007. WOJTYLA, K. J. Por suas próprias palavras. São Paulo: Cidade Nova, 2002. YAZBEK, M. C.; SILVA E SILVA, M. O. da. Das origens à atualidade da profissão: a construção da Pós-Graduação em Serviço Social no Brasil. In: CARVALHO, D. B. B.; 
SILVA E SILVA, M. O. da (Orgs.). Serviço Social, Pós-Graduação e Produção de

Conhecimento no Brasil. São Paulo: Cortez, 2005. p. 25-49. 